\title{
Anlotinib Plus S-I for Patients with EGFR Mutation-Negative Advanced Squamous Cell Lung Cancer with PS Scores of 2-3 After Progression of Second-Line or Later-Line Treatment
}

This article was published in the following Dove Press journal:

Cancer Management and Research

\author{
Xiao-Hong Xie* \\ Fei Wang* \\ Xin-Qing Lin \\ Yin-Yin Qin \\ Zhan-Hong Xie \\ Jie-Xia Zhang \\ Ming Ouyang \\ Cheng-Zhi Zhou
}

State Key Laboratory of Respiratory Disease, National Clinical Research Center of Respiratory Disease, Guangzhou Institute of the Respiratory Health, First Affiliated Hospital of Guangzhou Medical University, Guangzhou Medical University, Guangzhou 510120, People's Republic of China

*These authors contributed equally to this work
Correspondence: Cheng-Zhi Zhou State Key Laboratory of Respiratory Disease, National Clinical Research Center of Respiratory Disease, Guangzhou Institute of the Respiratory Health, First Affiliated Hospital of Guangzhou Medical University, Guangzhou Medical University,

Guangzhou, People's Republic of China

Tel +86-20-83062830

Email zhouchengzhi@gird.cn
Objective: The study aimed to analyze the efficacy and safety of combination regimen of anlotinib and S-1 for Chinese patients with EGFR mutation-negative advanced squamous cell lung cancer (SqCLC) with poor performance status (PS,2-3) after progression of secondline or later-line chemotherapy.

Methods: Clinical data of 70 SqCLC patients with PS scores of 2-3 treated in the First Affiliated Hospital of Guangzhou Medical University between January 1, 2018 to September 31, 2019 who failed second- or more-line treatment were analysed retrospectively. The patients were divided into two treatment groups: anlotinib (12mg) plus S-1 (25mg) combination group and anlotinib $(12 \mathrm{mg})$ monotherapy group. The efficacy and adverse reactions of the two groups were compared.

Results: In terms of the short-term efficacy, there were no significant differences in objective response rate (ORR) $(20.0 \%$ vs $10.0 \%, p=0.464)$ and disease control rate (DCR) $(75.0 \%$ vs $60.0 \%, p=0.181)$ between the two groups. As for the long-term efficacy, there was no significant difference in progression-free survival (PFS) between the two groups (3.87 \pm 0.29 months vs $3.00 \pm 0.24$ months, $p=0$. 11). The overall survival (OS) of patients in the combination group was longer than $\mathrm{S} 1$ group $(8.07 \pm 0.56$ months vs $6.17 \pm 0.42$ months, $p=0.022$ ).

Conclusion: Advanced SqCLC patients with higher PS scores still benefit from anlotinib and S-1 combination regimen, even after they failed second-line or later-line systemic treatment.

Keywords: anlotinib, S-1, advanced squamous cell lung cancer, performance status, efficacy

\section{Introduction}

Primary bronchogenic lung carcinoma is the most common malignant cancer worldwide. According to Globocan 2018, ${ }^{1}$ annually, lung cancer accounts for approximately 2.09 million (approximately 11.6\%) of the 18.1 million new cases of cancer and 1.76 million (approximately 18.4\%) of the 9.6 million deaths worldwide. Currently, lung cancer is the cancer with the highest incidence and mortality worldwide. It is the highest ranked cancer in terms of incidence and mortality among males. Among females, it has the second highest incidence (second to breast cancer) and the highest mortality. Most patients are already in advanced stage at the time of diagnosis, and the five-year survival rate is only about 5\%. Although 
targeted therapy and immunotherapy have significantly improved the survival and quality of life of such patients in recent years, the former is only appropriate in relatively few patients who test positive for a driver gene, whereas accessibility and efficacy of the latter make it impossible for most patients to benefit from it. Therefore, chemotherapy is still the common treatment for advanced lung cancer patients bearing negative driver genes. For patients with performance status (PS) scores $\geq 2$, best supportive care is still recommended by teh current National Comprehensive Cancer Network (NCCN) guidelines. ${ }^{2}$ Currently, there is little evidence and no uniform standard for the follow-up of patients who have progressed after second-line treatment. Therefore, follow-up treatment for patients with PS scores $\geq 2$ after progression of secondline treatment needs to be further investigated. In this study, a retrospective analysis of the efficacy and adverse events of anlotinib and S-1 in 70 patients with advanced squamous cell lung cancer (SqCLC) with PS scores of 2-3 after failure of second-line or later-line treatment was performed. This cohort of patients was regularly followed up to develop more effective treatment options.

\section{Patients and Methods}

\section{Patients}

The study subjects were 70 patients with a pathological diagnosis of squamous cell carcinoma of the lung with clinical stage IIIB, IIIC or IV. Patients tested negative for driver mutations. All patients exhibited progression after undergoing two or more systemic treatments, and the PS scores were between 2 and 3 after progression. After disease progression, oral anlotinib was administered to all patients. Of these patients, 40 were additionally given S-1.

\section{Methods}

The inpatient and outpatient data of the 70 patients in the First Affiliated Hospital of Guangzhou Medical University on January 1, 2018 and December 31, 2019 were retrospectively analysed, including imaging results, PS scores and adverse reactions after medication. Follow-up visits were conducted monthly. In addition, regular telephone follow-ups were conducted on the first day of each month. The last follow-up date was June 30, 2020. This retrospective study was approved by the ethics committee of First Affiliated Hospital of Guangzhou Medical University (2018-71) and used the masked data identifiers during data collection and analysis. Therefore, patient consent was waived in light of the retrospective and deidentified nature of the data presented in accordance with the Institutional Review Board. This study was conducted in accordance with the Declaration of Helsinki.

Diagnostic criteria: lung cancer was diagnosed according to the "2015 Chinese Primary Lung Cancer Diagnosis and Treatment Standards", ${ }^{3}$ classified according to the "2015 World Health Organization Classification of Lung Tumours", 4 and staged according to the "2017 8th edition of TNM classification". ${ }^{5}$ Efficacy evaluation was performed according to the Response Evaluation Criteria in Solid Tumors (RECIST) 1.1 standards, ${ }^{6}$ and evaluation of adverse reactions was based on version 4.0 of the Common Terminology Criteria for Adverse Events (CTCAE) ${ }^{7,8}$

\section{Treatments}

S-1-25 mg p.o. b.i.d., administration for four weeks and withdrawal for two weeks; anlotinib - $12 \mathrm{mg}$ p.o. q.d., administration for two weeks and withdrawal for one week until intolerance by the patient or death.

\section{Statistical Analysis}

SPSS software version 16.0 was used for statistical analysis. Count data are expressed as the number of cases or as a proportion (\%), and the $\chi^{2}$ test was used for comparisons between groups. Measurement data conforming to the normal distribution are expressed as mean \pm standard deviation (SD), and the $t$-test for independent samples was used for comparisons. The rank-sum test for independent samples was used for data not conforming to the normal distribution. Survival curves were plotted using the Kaplan-Meier method, and survival rates were compared using the Log rank test. Differences with $p$ values $<0.05$ were considered statistically significant.

\section{Results}

Of the 70 patients, 60 were males. Thirty-six male patients were in the combination chemotherapy group, while 24 males were in the monotherapy group. The median age of the two groups were $63.1 \pm 9.0$ years and $61.7 \pm 10.0$ years, respectively. Eighty percent of patients in the combination group had a history of smoking, with an average smoking index of $1205.6 \pm 540.0$ pack-years. Seventy percent of patients in the monotherapy group had a history of smoking, with an average smoking index of $1100.0 \pm 616.4$ packyears. The median PS score of the two groups after development of drug resistance was $3.3 \pm 0.5$ and $3.3 \pm 0.4$, 
respectively. The two groups of patients underwent systemic second-line treatment, and $25.0 \%$ of patients in the combination group underwent third- or higher-line treatment before inclusion in the study, while $23.3 \%$ of patients in the monotherapy group underwent third- or higher-line treatment. Eighty percent and $70 \%$ of patients in the combination group and single-drug group, respectively, had central SqCLC. With respect to lung comorbidities, chronic obstructive pulmonary disease (COPD), pneumonia and bronchiectasis were relatively common in the two groups; however, concomitant pneumonia was the most common. There was no significant difference in the clinical baseline data between the two groups of patients (Table 1).

\section{Short- and Long-Term Therapeutic Efficacy}

As of December 31, 2019, all patients of both groups exhibited disease progression but continued taking the medication. Twenty-eight patients died in the combination,

Table I Baseline Data of Patients

\begin{tabular}{|c|c|c|c|c|}
\hline Characteristic & $\begin{array}{l}\text { Anlotinib } \\
+S I\end{array}$ & Anlotinib & $\begin{array}{l}\text { Test } \\
\text { Value }\end{array}$ & $P$ value \\
\hline Sex (male/female) & $36 / 4$ & $24 / 6$ & $\chi^{2}=1.4$ & 0.308 \\
\hline Years & $63.1 \pm 9.0$ & $61.7 \pm 10.0$ & $\mathrm{t}=0.43$ & 0.67 \\
\hline Smokers [n (\%)] & $32(80.0 \%)$ & 21 (70.0\%) & $\chi^{2}=0.932$ & 0.334 \\
\hline \multirow[t]{2}{*}{ Smoking index } & 1205.6 & 1100.0 & $\mathrm{t}=0.42$ & 0.679 \\
\hline & \pm 540.0 & \pm 616.4 & & \\
\hline Stage $[\mathrm{n}(\%)]$ & & & $\chi^{2}=0.280$ & 0.991 \\
\hline IIIB & $8(20.0 \%)$ & $6(20.0 \%)$ & & \\
\hline IIIC & $10(25.0 \%)$ & $7(23.3 \%)$ & & \\
\hline IVA & $8(20.0 \%)$ & $5(16.7 \%)$ & & \\
\hline IVB & $10(25.0 \%)$ & $9(30.0 \%)$ & & \\
\hline IVC & $4(10.0 \%)$ & $3(1.0 \%)$ & & \\
\hline Performance Status & $3.0 \pm 0.6$ & $2.9 \pm 0.6$ & $\mathrm{t}=0.445$ & 0.507 \\
\hline Tumor location [n (\%)] & & & $\chi^{2}=0.932$ & 0.334 \\
\hline Central & 32 (80.0\%) & 21 (70.0\%) & & \\
\hline Peripheral & $8(20.0 \%)$ & $9(30.0 \%)$ & & \\
\hline Treatment line number [ $\mathrm{n}$ & & & $\chi^{2}=0.026$ & 0.872 \\
\hline (\%)] & & & & \\
\hline Thirdly - line & $30(75.0 \%)$ & $23(76.7 \%)$ & & \\
\hline Later - line & $10(25.0 \%)$ & 7 (23.3\%) & & \\
\hline $\begin{array}{l}\text { History of radiation } \\
\text { therapy }[n(\%)]\end{array}$ & $4(10.0 \%)$ & $4(13.3 \%)$ & $\chi^{2}=0.188$ & 0.717 \\
\hline \multirow{2}{*}{\multicolumn{5}{|c|}{ Pulmonary complications }} \\
\hline & & & & \\
\hline COPD & $6(15.0 \%)$ & $5(16.7 \%)$ & $\chi^{2}=0.036$ & 1.000 \\
\hline Pneumonia & 15 (37.5\%) & $12(40.0 \%)$ & $\chi^{2}=0.045$ & 0.832 \\
\hline
\end{tabular}

while in the single-drug group, 23 patients died. For shortterm efficacy (two cycles of medication), objective response rate (ORR) of the 32 patients was $9.4 \%$, and disease control rate (DCR) was $59.4 \%$. There was no statistically significant difference in either ORR $(20.0 \%$ vs $10.0 \%, p=0.464)$ or DCR $(75.0 \%$ vs $60.0 \%, p=0.181)$ between the groups (Table 2). For long-term efficacy, the progression-free survival (PFS) was $3.94 \pm 0.52$ months, and the OS was $7.86 \pm 0.63$ months. The PFS of the combination group was better than that of the single-drug group, but the difference was not statistically significant (3.87 \pm 0.29 vs $3.00 \pm 0.24$ months, $p=0$. 11) (Figure 1). The overall survival (OS) of the combination group was better than that of the monotherapy group, and the difference was statistically significant $(8.07 \pm 0.56$ vs $6.17 \pm 0.42$ months, $p=0.022$ ) (Figure 2).

\section{Changes of PS Score}

The PS score of the two groups of patients changed throughout the follow-up period (Table 3, Figure 3).

\section{Adverse Reactions}

During follow-up, adverse reactions such as fatigue, elevated blood pressure, abdominal pain and diarrhoea, abnormal skin pigmentation, and haemoptysis were observed in both groups of patients; however, no adverse event of grade 3 or higher requiring discontinuation (Table 4) was observed. Although the combination therapy group had a higher incidence of common adverse reactions than the monotherapy group, only the difference in dermal toxicity was statistically significant between the two groups $(83.33 \%$ vs $40.00 \%, p=0.000)$.

\section{Discussion}

Anlotinib is a novel, small-molecule, multi-targeted tyrosine kinase inhibitor that effectively inhibits tumour angiogenesis

Table 2 Outcome of Patients

\begin{tabular}{|l|l|l|l|l|}
\hline $\begin{array}{l}\text { Efficacy } \\
\text { Index }\end{array}$ & $\begin{array}{l}\text { Anlotinib } \\
\text { +SI }\end{array}$ & Anlotinib & $\begin{array}{l}\text { Test } \\
\text { Value }\end{array}$ & P value \\
\hline PR & 8 & 4 & & \\
SD & 22 & 14 & & \\
PD & 10 & 12 & & \\
ORR & $20.0 \%$ & $10.0 \%$ & 0.536 & 0.464 \\
DCR & $75.0 \%$ & $60.0 \%$ & 1.790 & 0.181 \\
PFS & $3.87 \pm 0.29$ & $3.00 \pm 0.24$ & 6.511 & 0.11 \\
OS & $8.07 \pm 0.56$ & $6.17 \pm 0.42$ & 5.248 & 0.022 \\
\hline
\end{tabular}




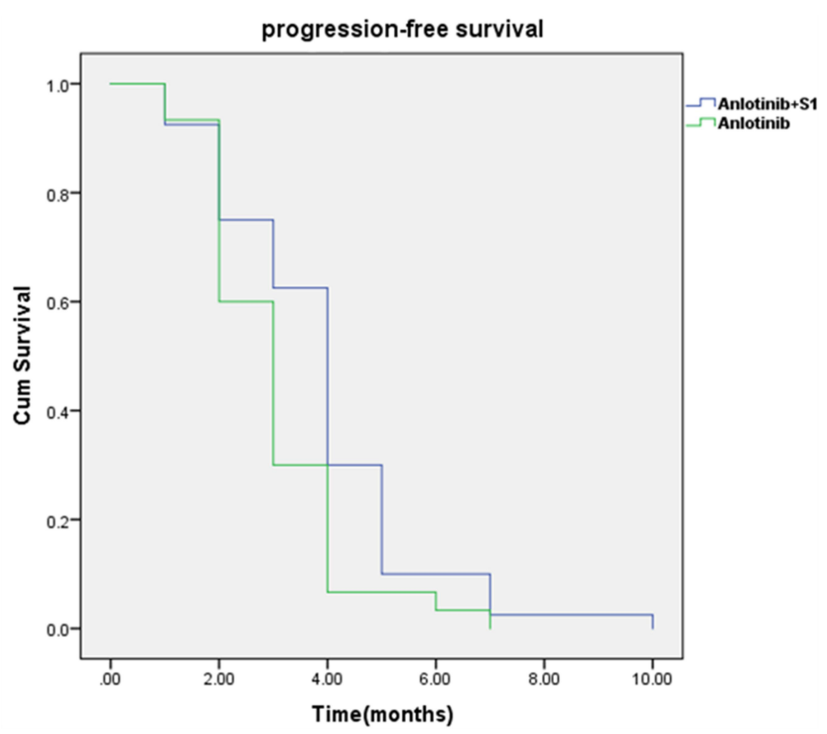

Figure I PFS of the combination group was not significantly higher than the monotherapy group $(3.87 \pm 0.29$ months vs $3.00 \pm 0.24$ months; $p>0.05)$.

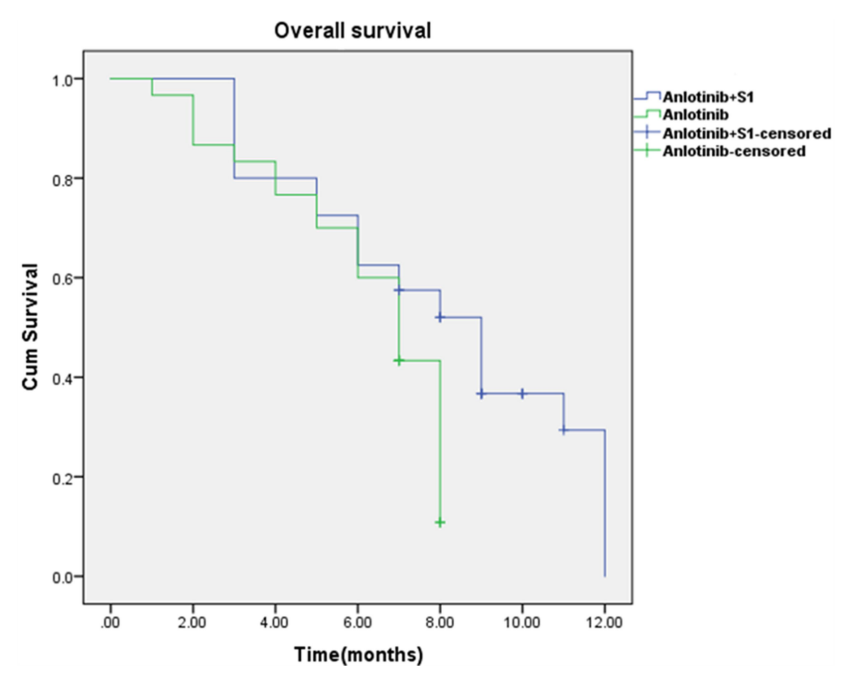

Figure 2 OS of the combination group was significantly higher than the monotherapy group $(8.07 \pm 0.56$ months vs $6.17 \pm 0.42$ months, $p<0.05)$.

and tumour growth through the inhibition of vascular endothelial growth factor receptor (VEGFR), plateletderived growth factor receptor (PDGFR), fibroblast growth factor receptor (FGFR), and c-Kit kinases. Anlotinib was approved by the National Medical Products Administration (NMPA) in China in 2008 as a third-line treatment for nonsmall cell lung cancer (NSCLC) based on the results of the ALTER0302 and ALTER0303 clinical trials. ${ }^{9,10}$ As an antiangiogenic drug, anlotinib has no clear PS score requirement, but contraindications should be avoided when it is administered, such as an increased risk of bleeding and active thrombosis. $^{11} \mathrm{~S}-1$ is a third-generation orally active
Table 3 PS Score Changes in Two Groups at Different Time Points

\begin{tabular}{|l|l|l|l|l|}
\hline Months & Anlotinib+SI & Anlotinib & Test Value & $P$ value \\
\hline 0 & $3.00 \pm 0.56$ & $2.93 \pm 0.58$ & 0.445 & 0.507 \\
1 & $3.00 \pm 0.68$ & $3.00 \pm 0.64$ & 0.015 & 0.903 \\
2 & $2.93 \pm 0.62$ & $3.17 \pm 0.95$ & 5.379 & 0.023 \\
3 & $3.25 \pm 1.03$ & $3.23 \pm 0.97$ & 0.222 & 0.639 \\
4 & $3.18 \pm 1.08$ & $3.33 \pm 1.10$ & 0.145 & 0.704 \\
5 & $3.34 \pm 1.10$ & $3.43 \pm 1.19$ & 1.115 & 0.295 \\
6 & $3.55 \pm 1.20$ & $3.63 \pm 1.27$ & 0.496 & 0.484 \\
\hline
\end{tabular}

derivative fluorouracil composed of tegafur, gimeracil and oteracil potassium. The blood concentration of 5-FU and its antitumor effects increase because of biotransformation of the prodrug tegafur, inhibition of its degradation using gimelazine, and reduction of its excretion using oteracil potassium. Two Japanese clinical studies ${ }^{12,13}$ indicated that S-1 alone or in combination with platinum is beneficial to patients with unresectable advanced NSCLC with mild adverse reactions, providing evidence for the application of S-1 in lung cancer treatment.

In the present study, the clinical data of 70 SqCLC patients with progression after failure of second- or higherline treatment and PS scores $\geq 2$ who received continued treatment with anlotinib and S-1 were retrospectively analysed. We found that most of these patients were elderly men who had relatively high smoking indices and comorbid lung diseases. These patients still benefited from anlotinib and S-1 after progression following second-line treatment, with an overall ORR of $17.14 \%$ and a DCR of $68.57 \%$; the overall PFS was $3.50 \pm 0.20$ months and the OS was $7.480 \pm 0.407$ months. Comparison between the two groups revealed no significant difference in short-term efficacy and PFS, but the OS of the combination group was better than that of monotherapy. With respect to the PS scores, the overall PS score in the first month after medication was lower than the score at baseline. The difference between the PS score of the combination group and monotherapy group in the first month after medication was statistically significant. Therefore, the combination of medications can be beneficial to patients in terms of improving the PS scores and based on their short- and long-term efficacies. The improved PS by this combination regimen make it possible for patients to have chances to receive further line treatment regimens. This is likely the main reason of OS difference between these two groups. Only two of the patients had mild haemoptysis after anlotinib treatment, and neither of the patients reached a level 


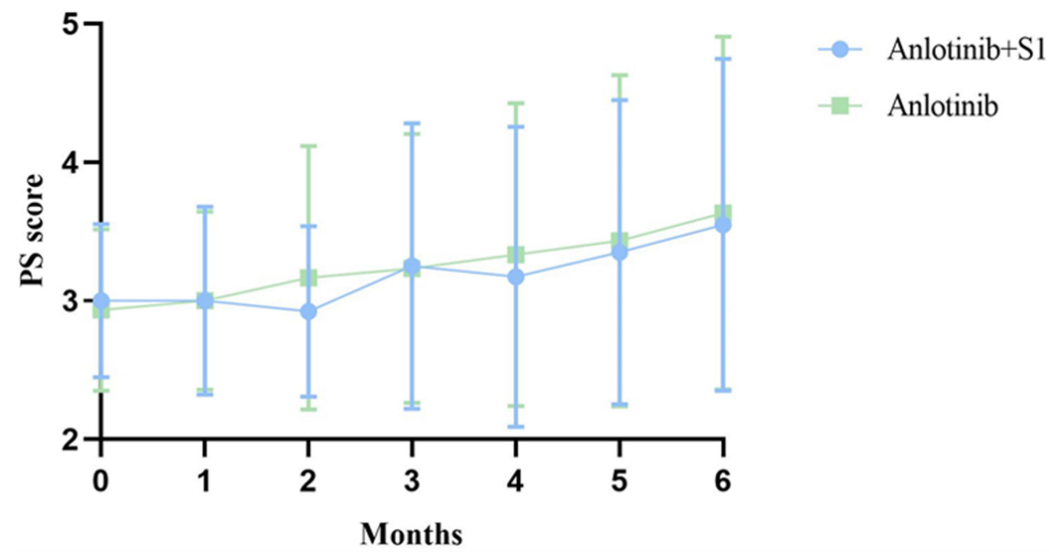

Figure 3 The PS score changes at different time points.

requiring drug discontinuation. With respect to skin toxicity, the proportion of patients with abnormal skin pigmentation was higher in patients treated with S-1 in combination with anlotinib, but this also did not reach a level requiring drug discontinuation. Although all patients had progressed to varying degrees during the subsequent follow-ups, they did not discontinue medications. There is little research on patients with poor PS scores after failure of multiline cancer treatment because the expected survival time is short and little attention is paid to this population. We have proposed the concept of "advanced severe lung cancer": ${ }^{14}$ advanced severe lung cancer does not refer to end-stage lung cancer,

Table 4 Adverse Event in Two Groups of Patients

\begin{tabular}{|c|c|c|c|c|}
\hline $\begin{array}{l}\text { Adverse Event } \\
\text { Rate (\%) }\end{array}$ & $\begin{array}{l}\text { Anlotinib } \\
+ \text { SI }\end{array}$ & Anlotinib & $\begin{array}{l}\text { Test } \\
\text { Value }\end{array}$ & $P$ value \\
\hline $\begin{array}{c}\text { Hemoptysis } \\
<\text { grade } 3 \\
\geq \text { grade } 3\end{array}$ & $\begin{array}{l}3(7.50) \\
0(0.00)\end{array}$ & $\begin{array}{l}3(10.00) \\
0(0.00)\end{array}$ & 0.137 & 1.000 \\
\hline $\begin{array}{l}\text { Abdominal pain } \\
\text { and diarrhea } \\
\quad<\text { grade } 3 \\
\geq \text { grade } 3\end{array}$ & $\begin{array}{l}22(55.5) \\
0(0.00)\end{array}$ & $\begin{array}{l}12(40.00) \\
0(0.00)\end{array}$ & 1.544 & 0.214 \\
\hline $\begin{array}{l}\text { Elevated blood } \\
\text { pressure } \\
\quad<\text { grade } 3 \\
\geq \text { grade } 3\end{array}$ & $\begin{array}{l}24(60.0) \\
0(0.00)\end{array}$ & $\begin{array}{l}12(40.0) \\
0(0.00)\end{array}$ & 2.745 & 0.098 \\
\hline $\begin{array}{l}\text { Weak } \\
\text { < grade } 3 \\
\geq \text { grade } 3\end{array}$ & $\begin{array}{l}26(65.00) \\
0(0.00)\end{array}$ & $\begin{array}{l}16(53.33) \\
0(0.00)\end{array}$ & 0.972 & 0.324 \\
\hline $\begin{array}{c}\text { Dermal toxicity } \\
\quad<\text { grade } 3 \\
\geq \text { grade } 3\end{array}$ & $\begin{array}{l}33(83.33) \\
0(0.00)\end{array}$ & $\begin{array}{l}12(40.00) \\
0(0.00)\end{array}$ & 13.487 & 0.000 \\
\hline
\end{tabular}

but refers to various factors inherently associated with the disease or caused by the application of anticancer agents, a PS score of 2-4, and stage IIIB, IIIC, and IV patients who have the greatest potential to benefit from existing systemic anticancer therapies. For this population of patients, the best supportive care and "high-efficacy, low-toxicity" drugs or "low-efficacy, low-toxicity" drugs, such as anlotinib and S-1, which can be maintained for a long period of time, can be beneficial. In addition, we believe that the PS score of lung cancer patients is characterized by "fluctuation" and "reversibility", which was confirmed in the present study. Additionally, the PS score of most of the patients with indications for a more active "two-drug combination" decreased or remained stable. Of the 70 patients, 11 had COPD and 17 had pneumonia. Therefore, in addition to the progression of the cancer itself, it cannot be ruled out that changes are associated with comorbidity. We indicated ${ }^{14}$ that by improving the management of comorbidities, the PS scores of patients are likely to improve and the patients may be able to tolerate systemic treatment again.

The present study has the following shortcomings: (1) it is a retrospective study with a small sample size and lacks rigorous conclusions; and (2) few patients with poor PS scores after failure of second-line treatment as acted as study subjects. Therefore, there is a lack of a basis for comparison. During patient follow-up, it is difficult to select the best supportive care, and patients with poor PS scores were not included. Thus, the benefit to this group of patients is greater than that to patients with the best supportive care could not be proven statistically.

\section{Conclusions}

For patients with advanced SqCLC with a PS score of 2-3 after failure of second-line or later-line treatments, 
subsequent treatment with anlotinib alone or in combination with S-1 may be beneficial over a short- and longterm period. The combination regimen is superior to monotherapy during OS, and no serious intolerable adverse reactions were observed.

\section{Acknowledgments}

The abstract of this paper was presented at the 2020 American Society of Clinical Oncology entitled "Anlotinib plus S-1 for patients with EGFR mutation-negative advanced squamous cell lung cancer with poor performance status after second or more -line treatment as an Abstract" (No. e21665). The abstract was published in "Abstracts" in Journal of Clinical Oncology (Volume 38, Issue 15_suppl) >: https://ascopubs. org/doi/abs/10.1200/JCO.2020.38.15 suppl.e21665?af=R\&).

This work was supported by State Key Laboratory of Respiratory Disease - The Independent project (No. SKLRD-QN-201720); State Key Laboratory of Respiratory Disease - The open project (No. SKLRD-OP -2018011); Guangdong High Level University Clinical Cultivation Project (No.2017-21020); and Wu Jieping Medical Foundation (No.320.6750.18125).

\section{Disclosure}

The authors report no conflicts of interest for this work.

\section{References}

1. de Martel C, Georges D, Bray F, Ferlay J, Clifford GM. Global burden of cancer attributable to infections in 2018: a worldwide incidence analysis. Lancet Glob Health. 2020;8(2):e180-e190. doi:10.1016/ S2214-109X(19)30488-7

2. Ettinger DS, Wood DE, Aggarwal C, et al. NCCN guidelines insights: non-small cell lung cancer, version 1.2020. J Natl Compr Canc Netw. 2019;17(12):1464-1472. doi:10.6004/jnccn.2019.0059
3. Zhi XY, Shi YK, Yu JM. Standards for the diagnosis and treatment of primary lung cancer (2015 version) in China. Chin J Oncol. 2015;37 (1):67-78.

4. Travis WD, Brambilla E, Nicholson AG, et al. The 2015 World Health Organization classification of lung tumors: impact of genetic, clinical and radiologic advances since the 2004 classification. $J$ Thorac Oncol. 2015;10(9):1243-1260. doi:10.1097/JTO.0000 000000000630

5. Goldstraw P, Chansky K, Crowley J, et al. The IASLC lung cancer staging project: proposals for revision of the TNM stage groupings in the forthcoming (Eighth) edition of the TNM classification for lung cancer. J Thorac Oncol. 2016;11(1):39-51. doi:10.1016/j.jtho.2015. 09.009

6. Eisenhauer EA, Therasse P, Bogaerts J, et al. New response evaluation criteria in solid tumours: revised RECIST guideline (version 1.1). Eur $J$ Cancer. 2009;45(2):228-247. doi:10.1016/j.ejca. 2008.10.026

7. Gao WJ, Liu YY, Yuan CR. International evaluation system for adverse events of chemotherapeutic drugs in cancer treatment: cTCAEv4.0. Tumor. 2012;32(2):142-144.

8. Grosu HB, Eapen GA, Jimenez CA, Morice RC, Ost D. Lung cancer screening: making the transition from research to clinical practice. Curr Opin Pulm Med. 2012;18(4):295-303. doi:10.1097/ MCP.0b013e3283548139

9. Han B, Li K, Zhao Y, et al. Anlotinib as a third-line therapy in patients with refractory advanced non-small-cell lung cancer: a multicentre, randomised Phase II trial (ALTER0302). $\mathrm{Br}$ $J$ Cancer. 2018;118(5):654-661. doi:10.1038/bjc.2017.478

10. Lu J, Zhong $\mathrm{H}$, Wu J, et al. Circulating DNA-based sequencing guided anlotinib therapy in non-small cell lung cancer. $A d v$ Sci (Weinh). 2019;6(19):1900721. doi:10.1002/advs.201900721

11. Zhao Y, Adjei AA. Targeting angiogenesis in cancer therapy: moving beyond vascular endothelial growth factor. Oncologist. 2015;20 (6):660-673. doi:10.1634/theoncologist.2014-0465

12. Kawahara M, Furuse K, Segawa Y, et al. Phase II study of S-1, a novel oral fluorouracil, in advanced non-small-cell lung cancer. Br J Cancer. 2001;85(7):939-943. doi:10.1054/bjoc.2001.2031

13. Okamoto I, Yoshioka H, Morita S, et al. Phase III trial comparing oral S-1 plus carboplatin with paclitaxel plus carboplatin in chemotherapy-naïve patients with advanced non-small-cell lung cancer: results of a west Japan oncology group study. J Clin Oncol. 2010;28 (36):5240-5246. doi:10.1200/JCO.2010.31.0326

14. Xie ZH, Zhou CZ, Qin YYQ, et al. Diagnosis and treatment strategy for advanced severe lung cancer. Chin J Pract Intern Med. 2019;39 (5):416-419.

\section{Publish your work in this journal}

Cancer Management and Research is an international, peer-reviewed open access journal focusing on cancer research and the optimal use of preventative and integrated treatment interventions to achieve improved outcomes, enhanced survival and quality of life for the cancer patient.
The manuscript management system is completely online and includes a very quick and fair peer-review system, which is all easy to use. Visit http://www.dovepress.com/testimonials.php to read real quotes from published authors. 